\title{
Presumed ocular histoplasmosis syndrome and linear streak lesions
}

\author{
F G BOTTONI, ${ }^{\text {A F DEUTMAN, }}$ AND A L AANDEKERK \\ From the 'University Eye Clinic, San Paolo Hospital, Milan, Italy, and the ${ }^{2}$ Institute of Ophthalmology, \\ University of Nijmegen, Nijmegen, The Netherlands
}

SUMMARY Five cases of subretinal neovascular membranes in the macula associated with punched out chorioretinal scars and linear streaks were seen in five Dutch patients. Clinically the fundus lesions are consistent with those of presumed ocular histoplasmosis syndrome (POHS) seen in the United States of America. Cutaneous serological testing for histoplasmin reactivity was negative in the three patients tested. Of special interest is the presence of linear streaks in association with POHS. They have not been previously described in patients from Europe with this syndrome.

Although the association of haemorrhagic macular lesions and histoplasmosis was noted as early as 1942, ' the syndrome of presumed ocular histoplasmosis (POHS) was not defined until 1959 by Woods and Wahlen. ${ }^{2}$ Their description of disciform lesions at the macula accompanied by multiple peripheral, discrete atrophic lesions was expanded to include peripapillary pigment epithelial atrophy ${ }^{3}$ and the absence of aqueous and vitreous inflammation. ${ }^{4} \mathrm{~A}$ fourth sign of linear peripheral streak lesions was eventually added to the common triad of POHS. ${ }^{56}$

POHS is a common disease in the United States of America, carrying a risk of bilateral loss of central vision. ${ }^{6}$ In Europe the syndrome is not so common and was mostly reported as being associated with negative histoplasmin reactivity..$^{711}$

Thus an acute haemorrhagic maculopathy very similar to the disciform reaction of the POHS, with or without peripapillary and peripheral changes has often been described by European authors under a variety of names. ${ }^{10-16}$

We present five cases of POHS seen at the Institute of Ophthalmology of the University of Nijmegen, with equatorial linear streak lesions as an interesting additional finding.

\section{Case reports}

CASE 1

A 42-year-old man presented in 1979 with a complaint of metamorphopsia in his right eye. Best

Correspondence to Dr F G Bottoni, University Eye Clinic, San Paolo Hospital, Via A. di Rudini 8, 20142 Milano, Italy. corrected visual acuity was $6 / 75$ in the right eye and $6 / 6$ in the left eye, with a myopic refraction. On ocular examination the media were clear, with no evidence of inflammation.

Fluorescein angiography of the right fundus disclosed subretinal neovascularisation in the macula, with histoplasma spots in the perifoveal area and inferior to the disc. At the equator, temporally and inferotemporally, linear streaks one to two disc diameters in width and parallel to the ora serrata, showed window defects, with occasional blockage of fluorescence corresponding to spots of hyperpigmentation. Similar lesions were seen in the left fundus (Fig. 1).

A histoplasmin skin test was negative. Spontaneous resolution of the former subretinal neovascular membrane with subsequent recurrences occurred during the seven-year follow up, leading eventually in the right eye to a visual acuity of $6 / 60$ and a dry scar.

\section{CASE 2}

This 22-year-old woman presented in 1982 with a sudden decrease in her left central vision. Her visual acuity was $6 / 6$ in the right eye and 6/400 in the left (emmetropic refraction). The media were clear, without evidence of inflammation.

Fluorescein angiography of the left eye revealed a subretinal neovascularisation inferonasal to the fovea. Either hyper- or hypofluorescent linear streaks according to the amount of pigment were seen in the equatorial area throughout the entire circumference of the globe. Posterior to the streaks 


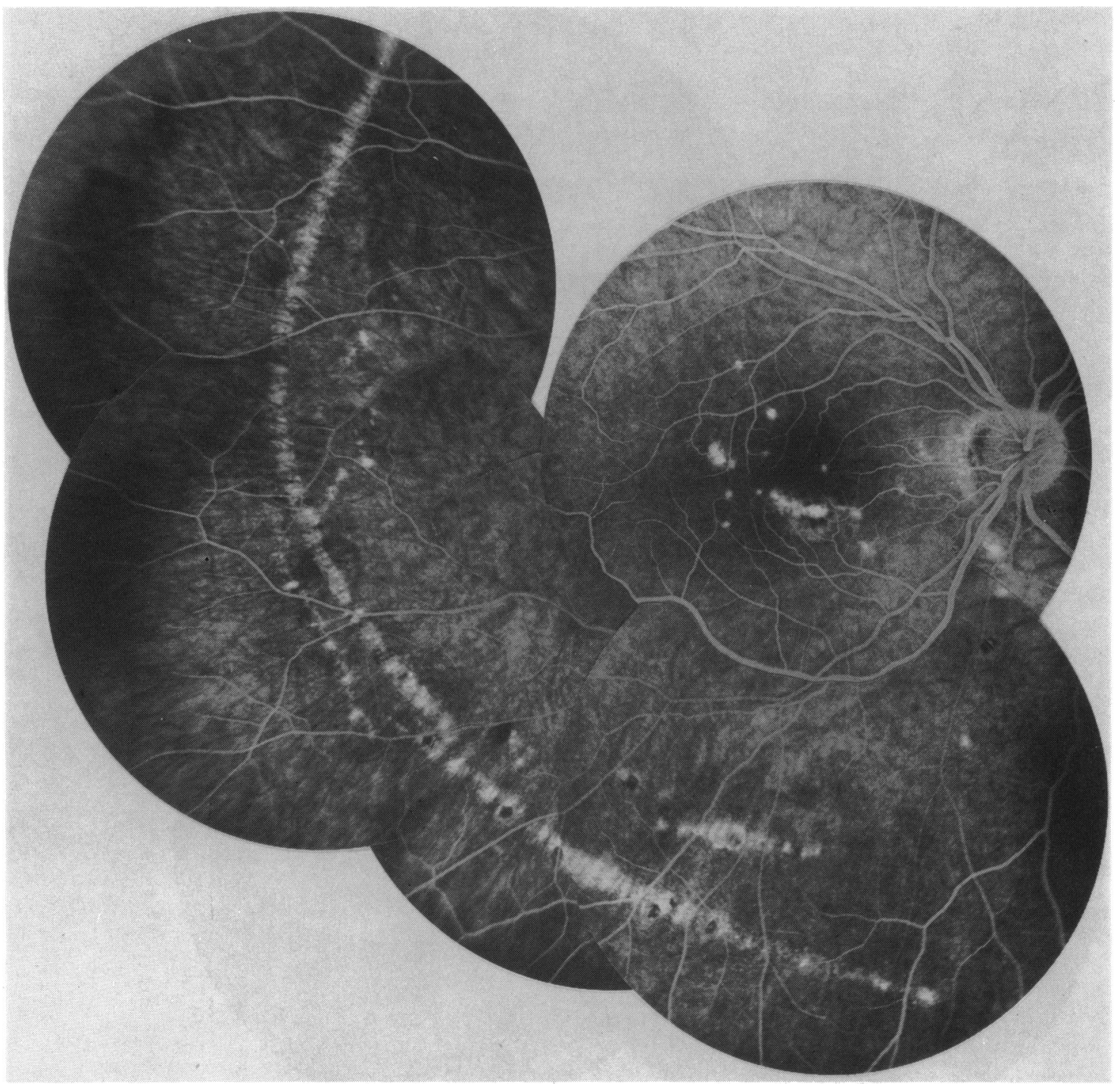

Fig 1 Case 1 (A) Fluorescein angiogram of the right fundus.

were a few histoplasma spots in the periphery of the inferior quadrants (Fig. 2).

A histoplasmin skin test was negative. Complete obliteration of the subretinal neovascular membrane was achieved with krypton laser photocoagulation, leading to a $6 / 6$ visual acuity in the left eye at a fiveyear follow-up.

\section{CASE 3}

This 49-year-old man, already diagnosed as having POHS in the right eye, presented at our institute in 1985 complaining of a two-week loss of vision in his left eye. Corrected vision was $6 / 15$ in both eyes with a myopic refraction. No evidence of ocular inflammation was detected.

On ophthalmoscopy the right eye showed a dry scar in the macula, histoplasma spots scattered either throughout the periphery or the posterior pole, and a linear streak inferotemporally. The left eye had a juxtafoveal neovascular membrane with linear streaks at the equator, inferiorly and inferotemporally. Posterior and anterior to the streaks were a few histoplasma spots (Fig. 3).

Tests for histoplasmosis were negative. At follow- 


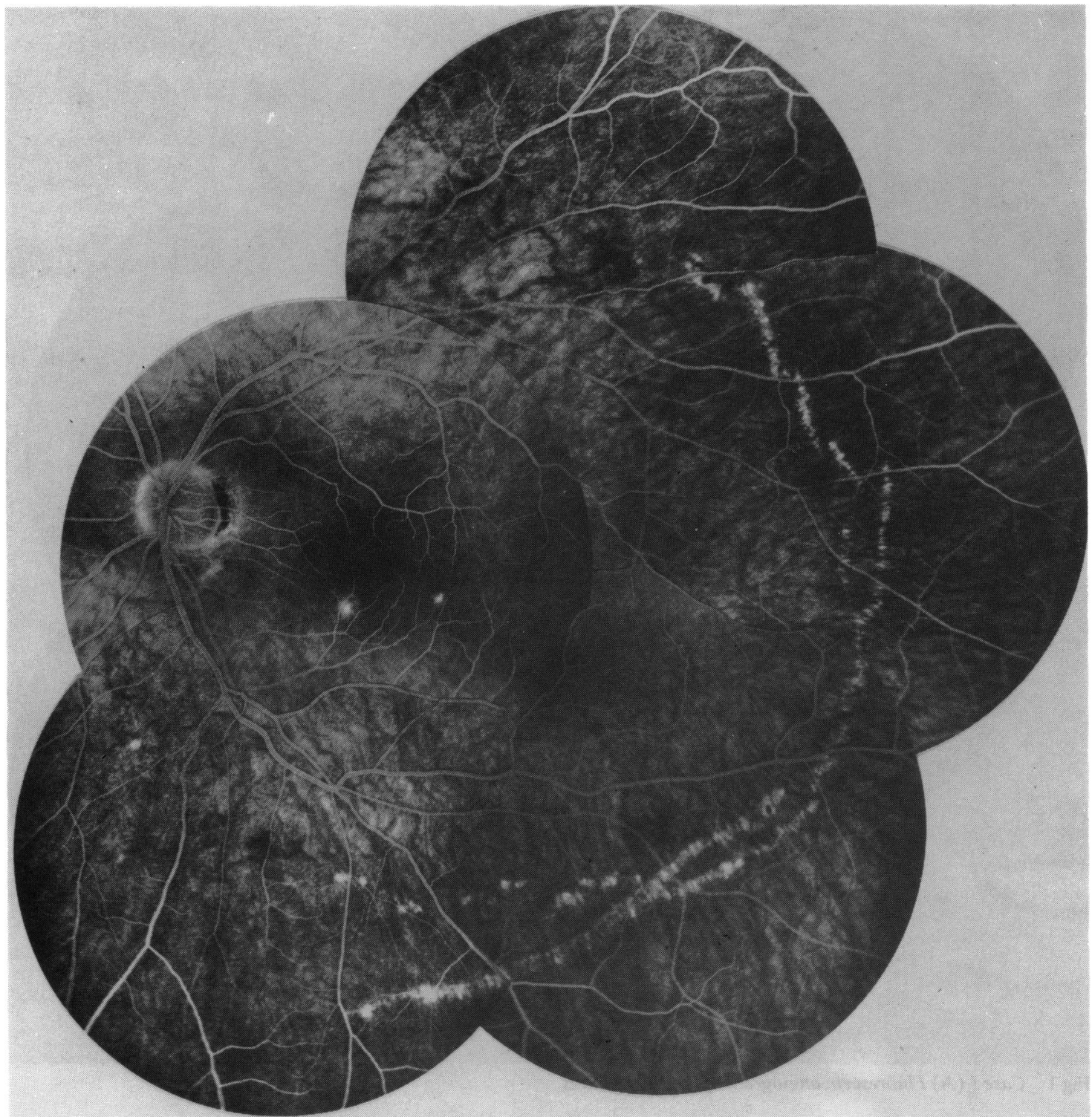

Fig 1 Case 1 (B) same patient, fluorescein angiogram of the left eye.

up, still in progress, the patient showed a marked improvement in the corrected visual acuity in the left eye to $6 / 75$, with a spontaneous involution of the subretinal neovascular membrane.

CASE 4

This 20-year-old woman presented first in 1982 complaining of loss of vision in her left eye. Corrected vision was $6 / 6$ in the right eye and 6/21 in the left eye with a myopic refraction. The media were clear, with no evidence of inflammation in either eye.

Fluorescein angiography revealed a subfoveal neovascular membrane as well as histoplasma spots in the left eye and peripapillary atrophy with the presence of a chorioretinal scar in the superior temporal quadrant in the right eye.

In 1985 she returned with a two-week history of loss of vision in the right eye. Corrected visual acuity 


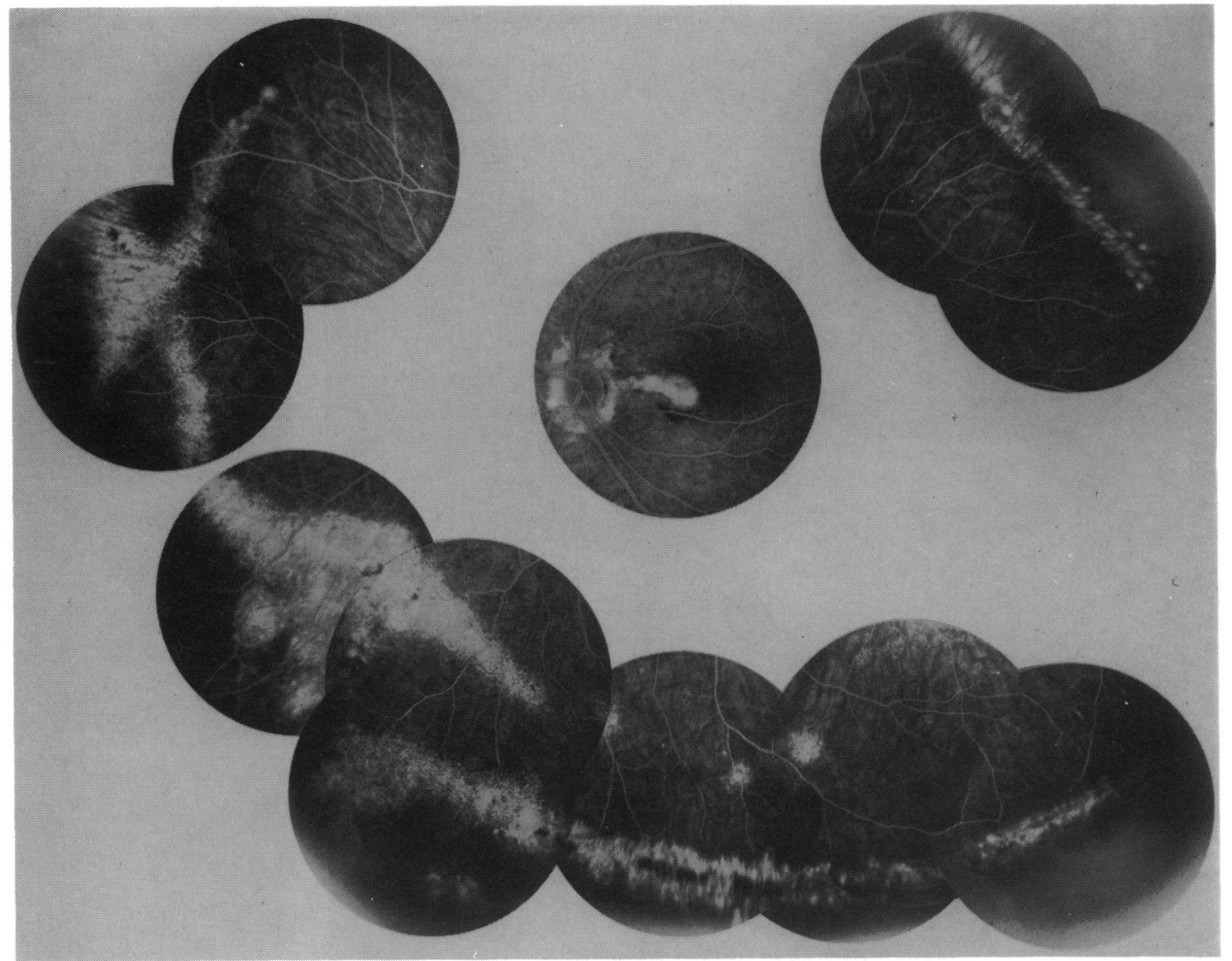

Fig 2 Case 2 fluorescein angiogram of the left fundus.

was $6 / 30$ in the right eye and $6 / 12$ in the left eye. There was still no evidence of inflammation in either eye.

Fluorescein angiography of the right eye showed juxtafoveal and subfoveal neovascular membranes as well as macular histoplasma spots. In the left eye there was staining of the dry scar in the macula, with subretinal bands of metaplastic retinal pigment epithelium, histoplasma spots throughout the fundus, and hypofluorescent linear streaks temporally and inferotemporally in the equatorial area (Fig. 4).

Spontaneous obliteration of the choroidal neovascularisation occurred in the left eye during a fiveyear follow-up. The final corrected visual acuity was $6 / 30$ in the right eye and $6 / 12$ in the left eye.

\section{CASE 5}

In 1984 this 39-year-old man presented for a routine examination. The visual acuity was $6 / 6$ in both eyes with an emmetropic refraction. The media were clear, without evidence of inflammation bilaterally.

Fluorescein angiography showed both eyes hyperfluorescent histoplasma spots and linear streaks temporally and inferotemporally (Fig. 5).

Follow-up examinations have shown a steady state.

\section{Discussion}

While typical POHS is common in the USA, the actual syndrome may be rare in Europe. Cutaneous and serological testing for histoplasmin reactivity in European patients with similar clinical pictures have been entirely negative. ${ }^{7-11}$ The incidence of positive results of histoplasmin skin tests in Europe is extremely low, ranging from 0 to $2 \% . .^{17}$

Since the aetiological association between this ocular syndrome and Histoplasma capsulatum infec- 


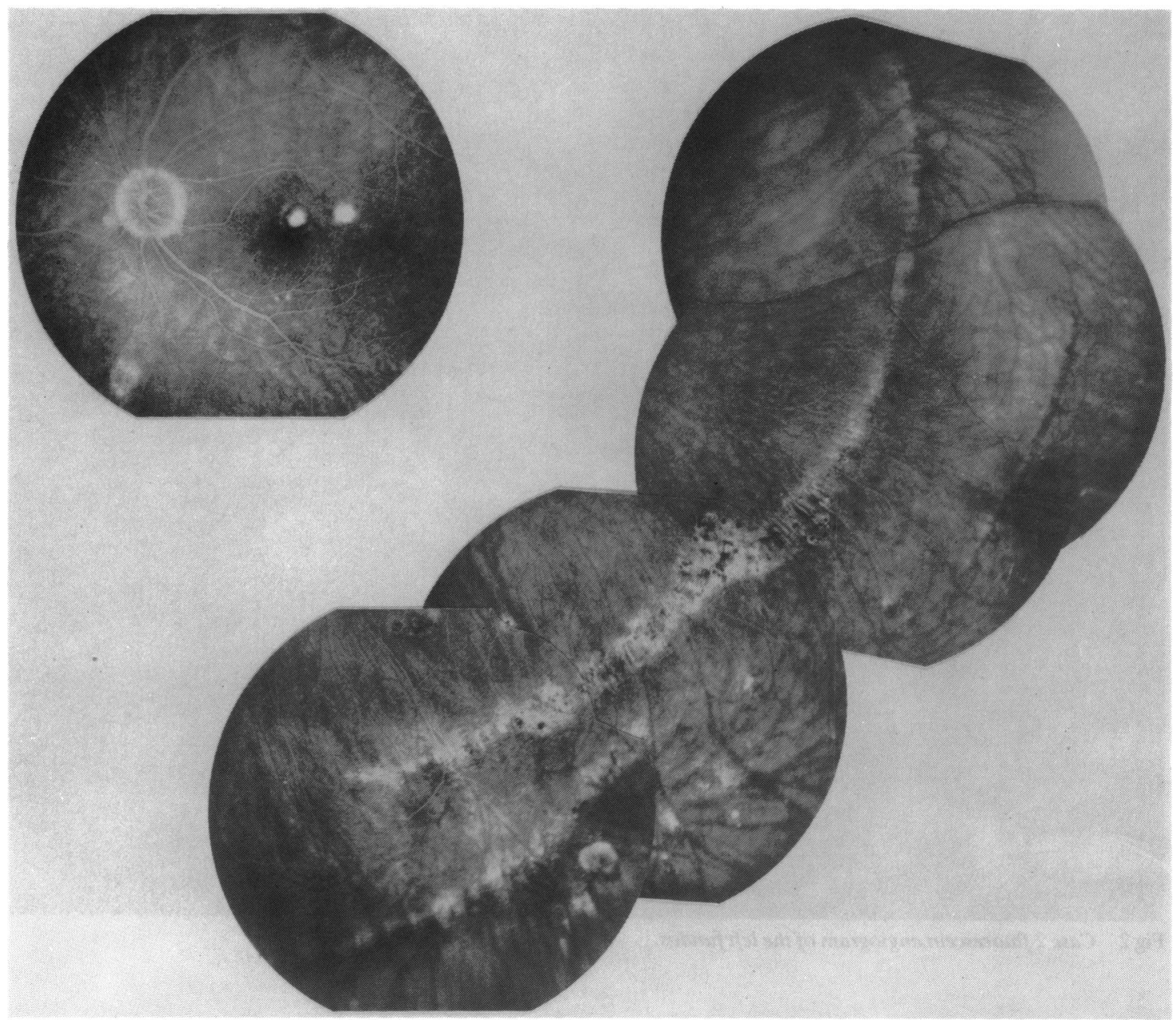

Fig 3 Case 3 fluorescein angiogram of the left eye.

tion rests solely on epidemiological data, and since these have not been entirely free of controversy,,$^{18}$ the diagnosis of POHS is based on the ophthalmoscopic finding of a neovascular lesion in the macula along with the presence of at least one atrophic scar-that is, histoplasma spot - in one or both eyes. ${ }^{19}$

Some of the cases described by European authors clinically resembled the POHS syndrome completely. Others did not, because an acute haemorrhagic maculopathy was the only sign described. The negative response to testing for histoplasmin reactivity was the reason these two groups were not diagnosed as presumed ocular histoplasmosis choroiditis. Thus they were seen as a single disease entity under various names. ${ }^{8-14}$
We agree with previous reports ${ }^{70-23}$ which indicated that it would be better to divide into two what was previously thought to be a single disease. In particular there are cases in young people where subretinal neovascularisation, at or near the fovea, resemble POHS, yet no other signs of POHS exist. These cases would have to be termed idiopathic and should be considered as a distinct group.

Our five cases show linear streaks associated with punched out chorioretinal scars (histoplasma spots) and haemorrhagic maculopathy in the absence of vitritis and anterior segment inflammation. A negative response to the histoplasmin skin test was found among the three tested cases. According to the Asbury rating system ${ }^{24}$ four of our patients with 


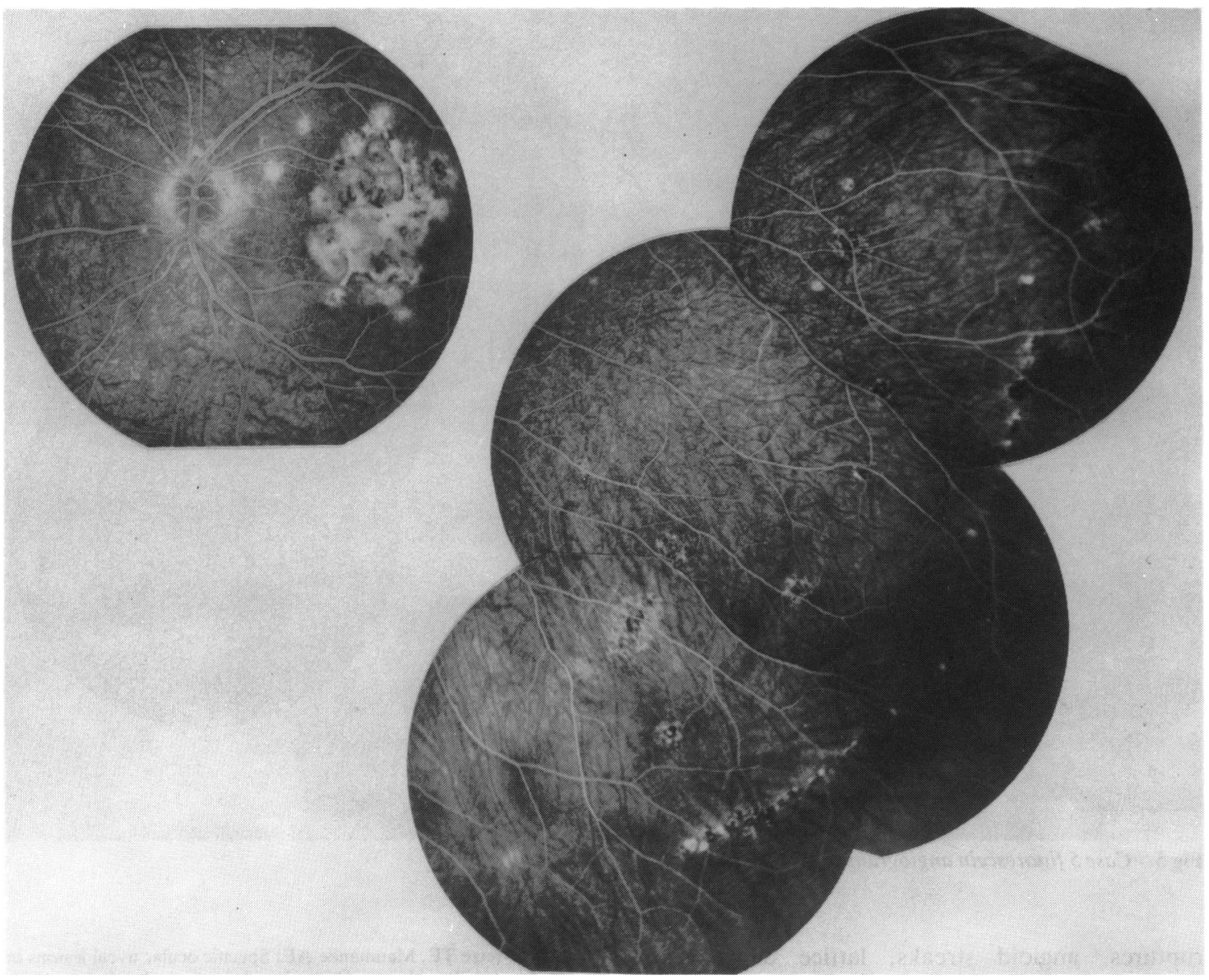

Fig 4 Case 4 fluorescein angiogram of the left eye.

streaks had an Asbury grade of four and one, case 2, of 3. High Asbury ratings (3 or 4) indicate typical POHS.

Two cases show some peculiarities. Case 5 has histoplasma spots and linear streaks bilaterally but no maculopathy. Case 4 was unilateral (left eye) at the first examination, with maculopathy and histoplasma spots only at the posterior pole of the left eye. Six months later the fellow eye was also involved (de novo), and the left eye showed a subretinal scar in the macula, an increased number of histoplasma spots scattered throughout the fundus, and linear streaks. This patient also had multiple lesions of the retinal pigment epithelium with recurrences similar to the ones originally described by Nozik and Dorsh ${ }^{25}$ and subsequently by other authors, ${ }^{26-29}$ a condition recently termed 'recurrent multifocal choroiditis'. This entity is a retinal pigment epithelium and choroidal inflammatory disorder characterised by multiple relapses and inflammatory signs in the vitreous and the anterior segment in the presence of POHS-like lesions. In contrast to that, our case did not show any inflammatory signs in the vitreous or in the anterior segment.

A review of the cases presented from Europe has revealed no previous reports showing the presence of linear streaks. An incidence of 5\% has been reported in patients with symptomatic POHS in the USA. ${ }^{5}$

The streaks may result from loss of choriocapillaris and retinal pigment epithelium. So far there is no explanation for the linear aggregation of histoplasma spots, which is probably the mechanism of streak formation.

Other causes of streak-like lesions in the retina must be differentiated from those seen in POHS. These include migrating parasites, choroidal 


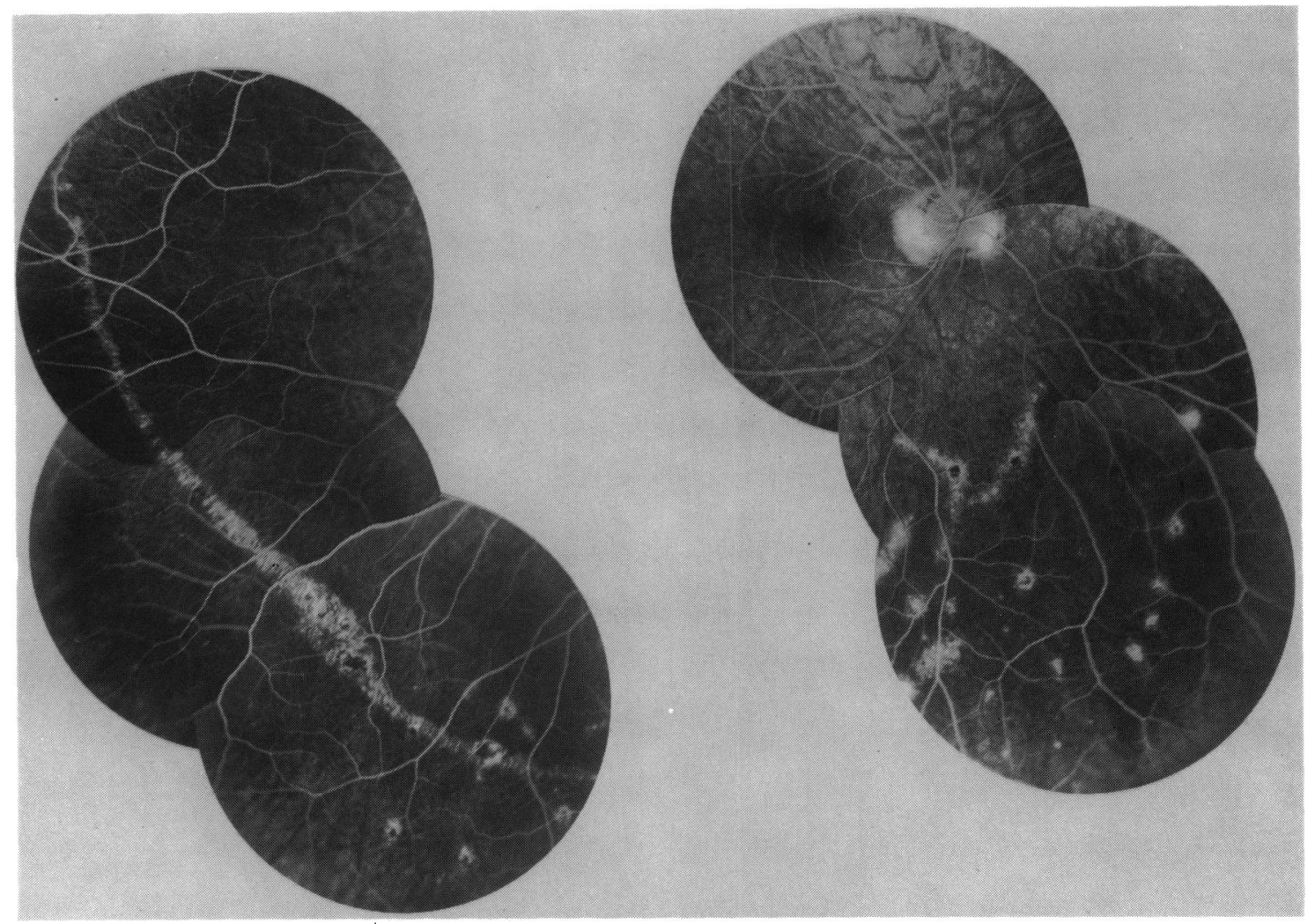

Fig 5 Case 5 fluorescein angiogram of the right eye.

ruptures, angioid streaks, lattice degeneration, demarcation lines, and streaks from ectatic areas, all of which can be distinguished by their characteristic appearances.

In conclusion, patients of European origin have fundus changes indistinguishable from POHS as seen in the USA; the abnormal signs include the circumferential linear scarring. The pathogenesis remains unproved. Schlaegel ${ }^{18}$ and we consider that the European syndrome may be caused by an agent similar to but different from Histoplasma capsulatum. Perhaps histoplasmosis is only one of several infections causing POHS.

\section{References}

1 Reid JD, Schere JH, Herbut PA, Irving H. Systemic histoplasmosis diagnosed before death and produced experimentally in guinea pigs. $J$ Lab Clin Med 1942; 27: 219-23.

2 Woods AC, Wahlen HE. The probable role of benign histoplasmosis in the etiology of granulomatous uveitis. Am J Ophthalmol 1960; 49: 205-20.

3 Schlaegel TF Jr, Kennery D. Changes around the optic nerve head in presumed ocular histoplasmosis. Am J Ophthalmol 1966; 62: $454-8$.
4 Van Metze TE, Maumenee AE. Specific ocular uveal lesions in patients with evidence of histoplasmosis. Arch Ophthalmol 1964; 71: 314-24.

5 Fountain JA, Schlaegel TF Jr. Linear streaks of the equator in the presumed ocular histoplasmosis syndrome. Arch Ophthalmol 1981; 99: 246-8.

6 Gass JDM. Pathogenesis of disciform detachment of the neuroepithelium. V: Disciform macular degeneration secondary to focal choroiditis. Am J Ophthalmol 1967; 63: 661-87.

7 François J, De Laey JJ, Dakir M. Choroidopathie maculaire hémorragique chez les sujets jeunes. Bull Soc Belge Ophthalmol 1974; 167: 664-78.

8 Braunstein RA, Rosen A, Bird AC. Ocular histoplasmosis syndrome in the United Kingdom. Br J Ophthalmol 1974; 58: 893-8.

9 Schildberg P, Wessing A, Eller B. Histoplasmin Hauttest bei fokaler hämorrhagischer Choroiditis. Klin Monatsbl Augenheilkd 1975; 166: 236-41.

10 Craandijk A. Focal macular choroidopathy. The Hague: Junk, 1979.

11 Saraux H, Le François A, Offret $H$. La choroidopathie maculaire hémorragique du sujet jeune ou pseudohistoplasmose. J Fr Ophthalmol 1979; 2: 349-54.

12 Notting JGA, Deutman AF, Van Der Werf PJP. Erscheinungsbild und behandlung makularer. Lasionen bei multifokaler choroiditis (presumed histoplasmosis). Klin Monatsbl Augenheilkd 1975; 166: 629-36.

13 Saari M. Disciform detachment of the Macula. Acta Ophthalmol (Kbh) 1977; 55: 525-9. 
14 Flage T, Bradberg Sand A, Syrdalen P. Haemorrhagic maculopathy in young adults. Acta Ophthalmol (Kbh) 1977; 55: 489-95.

15 Bonnet M, Dubost-Perret P, Grange JD. Etude de 29 cas de neovaisseaux choroidiens idiopathiques du sujet jeune (syndrome de pseudohitstoplasmose) suivis depui 6 mois a 11 ans. Bull Soc Fr Ophthalmol 1981; 11: 1059-61.

16 Harstad HK, Guldsten H. Focal macular choroidopathy. Acta Ophthalmol (Kbh) 1983; 61: 1067-73.

17 Ellis FD, Schlaegel TF Jr. The geographic localization of presumed histoplasmic choroiditis. Am J Ophthalmol 1973; 75: 953-6.

18 Schlaegel TF Jr. Ocular histoplasmosis. New York: Grune and Stratton, 1977.

19 Macular photocoagulation Study Group. Manual of procedures. Baltimore: MPS Coordinating Center, 1983: chapter 11.

20 Cleasby GW. Idiopathic focal subretinal neovascularization. Am J Ophthalmol 1976; 81: 590-6.

21 Macular Photocoagulation Study Group. Argon laser photocoagulation for idiopathic neovascularization. Results of a randomized clinical trial. Arch Ophthalmol 1983; 101: 1358-61.

22 Soubrane G, Koenig F, Coscas G. Choroidopathie maculaire hémorragique du sujet jeune. J Fr Ophthalmol 1983; 6: 24-34.
23 Bottoni FG, Deutman AF. Idiopathic subretinal neovascular membranes in the macula (hemorrhagic macular choroidopathy of young adults). Clinical report and effectiveness of laser treatment. Doc Ophthalmol 1986; 64: 311-43.

24 Asbury T. The status of presumed ocular histoplasmosis including a report of a survey. Trans Am Ophthalmol Soc 1966; 64: 371400.

25 Nozik RA, Dorsch WA. New chorioretinopathy associated with anterior uveitis. Am J Ophthalmol 1973; 76: 758-62.

26 Cantrill HL, Folk JC. Multifocal choroiditis associated with progressive subretinal fibrosis. Am J Ophthalmol 1986; 101: 170 80.

27 Morgan C, Schatz H. Recurrent multifocal choroiditis. Ophthalmology 1986; 93: 1138-43.

28 Doran RML, Hamilton AM. Disciform macular degeneration in young adults. Trans Ophthalmol Soc UK 1982; 102: 471-80.

$29 \mathrm{Kim}$ MK, Chan CC, Belfort R Jr, et al. Histopathologic and immunohistopathologic features of subretinal fibrosis and uveitis syndrome. Am J Ophthalmol 1987; 104: 15-23.

Accepted for publication 20 October 1988. 